\title{
Effects of Deletions in Pichia pastoris RTG Genes on Phenotype and AOX1 Expression
}

\author{
A. M. Rumyantsev*, G. A. Soloviev, A. V. Slepchenkov, E. V. Sambuk \\ Department of Genetics and Biotechnology, St. Petersburg State University, St. Petersburg, Russia \\ Email: *rumyantsev-am@mail.ru
}

How to cite this paper: Rumyantsev, A.M., Soloviev, G.A., Slepchenkov, A.V. and Sambuk, E.V. (2018) Effects of Deletions in Pichia pastoris RTG Genes on Phenotype and $A O X 1$ Expression. Advances in Microbiology, 8, 439-450.

https://doi.org/10.4236/aim.2018.85029

Received: April 10, 2018

Accepted: May 28, 2018

Published: May 31, 2018

Copyright $\odot 2018$ by authors and Scientific Research Publishing Inc. This work is licensed under the Creative Commons Attribution International License (CC BY 4.0).

http://creativecommons.org/licenses/by/4.0/

\begin{abstract}
Methylotrophic yeast Pichia pastoris is an object of modern biotechnology. Decisive understanding of gene regulation mechanisms is essential for successful protein production. In this study, we investigated the effect of deletions in $P$. pastoris genes encoding proteins, homologous to $S$. serevisiae Rtg1p, Rtg 2p, Msn2p and Msn4p. It was shown, that deletion in PpRTG1 gene results in inability of $P$. pastoris to grow on medium with methanol as a carbon source and ammonium sulfate as a source of nitrogen. We also demonstrate that deletions in $P p R T G 1$ and $P p R T G 2$ decrease activity of $A O X 1$ promoter.
\end{abstract}

\section{Keywords}

Pichia pastoris, $A O X 1$, Tor-Kinase, Retrograde Regulation Pathway

\section{Introduction}

Methylotrophic yeast Pichia pastoris is widely used in modern biotechnology as a recombinant protein production host [1]. However, from the genetic point of view, this type of yeast has not been studied enough. Most studies were devoted to specific recombinant proteins production and fermentation strategies. Sequencing of $P$. pastoris genome significantly accelerated research in the field of genetics and physiology of this species [2].

All methylotrophic yeasts have a similar mechanism of methanol utilization, which is called "MUT pathway" (methanol utilization pathway) [3]. At the first stage, methanol is oxidized to formaldehyde by specific enzyme-alcohol oxidase ( $A O X$ EC 1.1.3.13). A toxic byproduct of this reaction-hydrogen peroxide is neutralized by catalase (Cat EC 1.11.1.6). Both of these processes occur in peroxisomes [4]. Formaldehyde either enters assimilation pathway by condensation with xylulose-5-phosphate, or is oxidized by dehydrogenases to produce 
energy [3]. P. pastoris is an obligate aerobe and its energy metabolism strictly depends on mitochondria. Thus, during methanol utilization peroxisomes and mitochondria function in $P$. pastoris should be coordinated by a regulatory system.

Promoter of the alcohol oxidase 1 ( $A O X 1)$ gene is extremely strong and is widely used in biotechnology for heterologous genes expression [5]. That is why the regulation of this gene is of particular interest. $A O X 1$ and other genes of MUT pathway (MUT-genes) are repressed when $P$. pastoris are grown on glucose or glycerol and are induced when methanol is used as the sole carbon source [6].

Previously we have shown that proline or glutamate as the sole sources of nitrogen lead to a decrease in the level of $A O X 1$ and MUT-genes transcription if compared with ammonium sulfate or glutamine [7]. Genes involved in peroxisome biogenesis and functioning ( $P E X$-genes) are regulated in the same manner [8]. Addition of rapamycin to the culture media reduces the negative effect of proline on $A O X 1$ expression, which implies that Tor-kinase plays a key role in establishing this regulation [8].

In $S$. cerevisiae cells there are two Tor-kinase complexes (TORC), with Torlp and Tor $2 p$ being their main components [9]. TORC1 plays key role in regulation of nutrient uptake and intermediary metabolism [10]. Nitrogen catabolite repression (NCR) is established by TORC1 via regulation of GATA-family transcription factors such as Gln3p. If preferred nitrogen sources (glutamine or ammonia) are present in the media, TORC1 activity leads to association of Gln3p with its cytoplasmic anchor Ure2p. If only poor nitrogen sources (e.g. proline or urea) are available, Gln3p is released from Ure2p and transported to the nucleus, where it activates expression of NCR sensitive genes [10] [11].

TORC1 is also involved in retrograde regulation pathway providing interorganelle communication between mitochondria, peroxisomes, and nucleus. In this pathway basic helix-loop-helix (bHLH) transcription factors Rtglp and Rtg3p regulate expression of genes encoding enzymes required for tri-carboxylic acid cycle intermediates synthesis [12] [13]. When inactive, Rtg1p/Rtg3p complex is sequestered in cytoplasm by Mks1p. Activation of another regulatory protein Rtg2 leads to release of Rtg1p/Rtg3p complex, its transport to the nucleus and expression of Rtg-dependent genes [12].

TORC1 activity plays a key role in environmental stress response (e.g. nutrient limitation) via regulation of $\mathrm{Zn}$-finger transcription factors Msn2p, Msn4p and Gis1p. Also in $S$. cerevisiae TORC1 is involved in regulation of protein synthesis, ribosome biogenesis, cell cycle, cell size and autophagy [14].

In the present work we searched for transcription factors that are involved in regulation of $A O X 1$ by Tor-kinase in $P$. pastoris.

\section{Materials and Methods}

\subsection{Plasmids}

pJET1.2/blunt plasmid (Thermo Fisher scientific) was used for cloning of 
$P p R T G 1, P p R T G 2$ and $P p M S N 2 / 4$ PCR products that were amplified using Rtg1F/Rtg1R, Rtg2F/Rtg2R and MsnF/MsnR primers respectively. Resulting pJET1.2-PpRTG1, pJET1.2-PpRTG2 and pJET1.2-PpMSN2/4 plasmids contained 941 bp fragment with $P p R T G 1$ coding sequence, $1655 \mathrm{bp}$ fragment with $P p R T G 2$ coding sequence and $944 \mathrm{bp}$ fragment with $P p M S N 2 / 4$ coding sequence respectively. pPICZ $\alpha$ A plasmid (Thermo Fisher scientific) was used as a template for amplification of zeocin resistant gene ZeoR using ZeoF/ZeoR primers. SacI and EcoRI sites were introduced within the primers, while BamHI and $B s r G I$ sites already existed within the amplified sequence. ZeoR PCR product was also cloned in $p J E T 1.2 /$ blunt. Than it was cloned into 1) pJET1.2-PpRTG1 and pJET1.2-PpRTG2 using SacI and BsrGI restriction sites and into 2) pJET1.2-PpMSN2/4 using BamHI and EcoRI sites. Resulting pJET1.2-PpRTG1 $\triangle Z e o R, p J E T 1.2-P p R T G 2 \triangle Z e o R$ and pJET1.2-PpMSN2/4 $\triangle Z e o R$ plasmids contain $Z e o R$ gene flanked by parts of $P p R T G 1, P p R T G 2$ and $P p M S N 2 / 4$ sequences respectively (Figure 2(a)).

\subsection{Strains}

P. pastoris strains presented in Table 1 were used. tr2-1-GS115 was derived previously from the original $P$. pastoris strain GS115 (his4) (Invitrogen). This strain lacks native ACP activity and carries a reporter acid phosphatase (ACP) PHO5 gene of $S$. cerevisiae under the control of $A O X 1$ gene promoter [7] [8]. Other strains presented in this study were derived from tr2-1-GS115 by transformation with deletion cassettes.

The bacterial E. coli strain DH5 $\alpha$ [F'phi80dlacZ delta (lacZYA_argF) U169 deo $\mathrm{R}$ recA1 endA1 hsdR17 (rK- mK+) phoA supE44 lambda_thi_1 gyrA96 reIA1/F' proAB+ laclqdeltaM15 Tn10 (tetr)] was used for the construction of plasmids.

\subsection{Culture Media and Conditions}

Synthetic media MN, MP, GN, GP and P were used in this study. All variations of synthetic media contained per $1 \mathrm{~L}$ : $100 \mathrm{ml}$ of $0.1 \mathrm{M} \mathrm{Na}$-citrate buffer $\mathrm{pH} 4.5$; $0.5 \mathrm{~g} \mathrm{MgSO}_{4} \cdot 7 \mathrm{H}_{2} \mathrm{O} ; 0.4 \mathrm{~g} \mathrm{CaCl}_{2} ; 1 \mathrm{~g} \mathrm{~K}_{2} \mathrm{PO}_{4}$; vitamins and trace metal. GN, GP contained $1 \%$ glycerol as a sole carbon source, and MN, MP contained $1 \%$ methanol. Ammonium sulfate was added to MN, GN media in concentration 0.46 $\mathrm{g} / \mathrm{L}$. MP, GP and P contained proline in concentration $0.46 \mathrm{~g} / \mathrm{L}$. For ACP activity

Table 1. P. pastoris strains used in this study.

\begin{tabular}{ccc}
\hline Strain & Genotype & Source of strain \\
\hline $\operatorname{tr} 2-1-\mathrm{GS} 115$ & $P A O X 1-P H O 5$ HIS4 phox & {$[7]$} \\
$\Delta \mathrm{rtg} 2-\mathrm{GS} 115$ & $P A O X 1-P H O 5$ HIS4 phox Pprtg2::ZEO & This study. \\
$\Delta \mathrm{msn} 2 / 4-\mathrm{GS} 115$ & $P A O X 1-P H O 5$ HIS4 phox Ppmsn2/4::ZEO & This study. \\
$\Delta \mathrm{rtg} 1-\mathrm{GS} 115$ & $P A O X 1-P H O 5$ HIS4 phox Pprtg1::ZEO & This study.
\end{tabular}


measurements $P$. pastoris cells were grown at $25^{\circ} \mathrm{C}$ in $30 \mathrm{ml}$ volumes. For plates $24 \mathrm{~g} / \mathrm{L}$ of agar was added to the media. Plates were incubated at $30^{\circ} \mathrm{C}$.

YPDS media containing $20 \mathrm{~g}$ of glucose, $20 \mathrm{~g}$ of peptone and $10 \mathrm{~g}$ of yeast extract and $182 \mathrm{~g}$ of sorbitol per $1 \mathrm{~L}$ was used for electroporation.

LB medium was used to cultivate bacterial strains. E. coli strains were grown at $37^{\circ} \mathrm{C}$.

\subsection{Oligonucleotides}

All oligonucleotides used in this study are presented in Table 2. The Primer 3 program was used to select primers for PCR (http://primer3.sourceforge.net/).

\subsection{Molecular Methods}

The bacterial transformation and plasmid isolation from E. coli was carried out in accordance with standard methods [15]. The isolation of DNA and yeast transformation was carried out according to [16] and [17].

PCR was performed according to the recommendations of the manufacturer of reagents (Thermo Fisher scientific). Pfu-polymerase was used when fragments were amplified for further cloning. Taq-polymerase was used for PCR analysis. Reactions were set in $25 \mathrm{uL}$ volumes. $20 \mathrm{ng}$ of plasmid DNA or $200 \mathrm{ng}$ of gDNA was used as a template. Primer annealing step was performed at $52^{\circ} \mathrm{C}$.

DNA hydrolysis with restriction endonucleases was performed using the buffers and conditions recommended by the manufacturer of the enzymes (Thermo Fisher scientific). Dephosphorylation of vectors was done using FastAP Thermosensitive Alkaline Phosphatase (Thermo Fisher scientific). DNA ligation was performed using T4 DNA Ligase (Thermo Fisher scientific). Electrophoresis of DNA was performed in $1 \%$ agarose gel according to [15]. Purification of DNA from agarose gels was performed using Cleanup Standard kit according to the recommendations of the manufacturer (Evrogen).

ACP activity was determined qualitatively [18] and quantitatively [19]. The specific activity of ACP was designated as the ratio of the optical density at 410

Table 2. Oligonucleotides used in this study.

\begin{tabular}{cc}
\hline Primer & Sequence 5’ $\mathbf{3}^{\prime}$ \\
\hline ZeoF & GAGCTCAGACCTTCGTTTGTGCG \\
ZeoR & GAATTCTAAAGCCTTCGAGCGTC \\
Rtg1F & TTCCTCTCCACTAGAATCAG \\
Rtg1R & AAAAGGTGGAGTAGTGTGG \\
Rtg2F & ACTCCGTACTCTATTTGCCAGC \\
Rtg2R & TTGGTTGTAAACTGGCAATTCTG \\
MsnF & GTAGCCTGTTCCAGCAG \\
MsnR & CTCATTCGTGTCTATGGAC \\
\hline
\end{tabular}


$\mathrm{nm}$ to the density of cell suspension at $600 \mathrm{~nm}$.

Statistical analysis was performed using the Past3 program.

\section{Results}

\section{1) Nitrogen catabolite repression and $A O X 1$ regulation by proline}

Our previous results allowed suggesting that $A O X 1$ and other $M U T$-genes are repressed via Tor-signaling pathway in media with methanol and proline as sole nitrogen source [8]. Here we investigated if NCR mechanisms are involved in such regulation. In $S$. cerevisiae NCR occurs if glutamine or ammonium are present in the media and results in repression of genes involved in metabolism of poor nitrogen sources, such as proline.

P. pastoris tr2-1-GS115 strain ( $P A O X 1-P H O 5$ HIS4 phox), which was constucted earlier, contains $S$. cerevisiae acid phosphatase (ACP) PHO5 reporter gene under the control of the $A O X 1$ gene promoter. This strain was grown in media with methanol. Media also contained ammonium sulfate at standard concentration $(0.46 \% \mathrm{w} / \mathrm{v})$ and proline at different concentrations $(0.11 \%$, $0.23 \%, 0.34 \%$ and $0.46 \%$ ). After 40 hours of cultivation ACP specific activity was measured in the yeast culture (Figure 1(a)).

The figure shows that $A O X 1$ promoter is repressed by proline even at low concentrations, despite the fact that rich nitrogen source, ammonium sulfate, is present in the media. These results allow suggesting that the mechanisms of nitrogen catabolite repression are not involved in the observed regulation of the $A O X 1$ promoter by proline.

Recent studies demonstrated that $P$. pastoris can utilize some amino acids (e.g. glutamate) as sole source of carbon and nitrogen [20]. To study if proline can be used by $P$. pastoris in such way, tr2-1-GS115 strain was placed in $10 \mu \mathrm{l}$ of cell suspensions $\left(10^{6}, 10^{5}, 10^{4}\right.$, and $10^{3}$ cells per $\left.\mathrm{ml}\right)$ on the plates with mineral media (P) containing only proline as carbon and nitrogen source (Figure $1(\mathrm{~b})$ ).

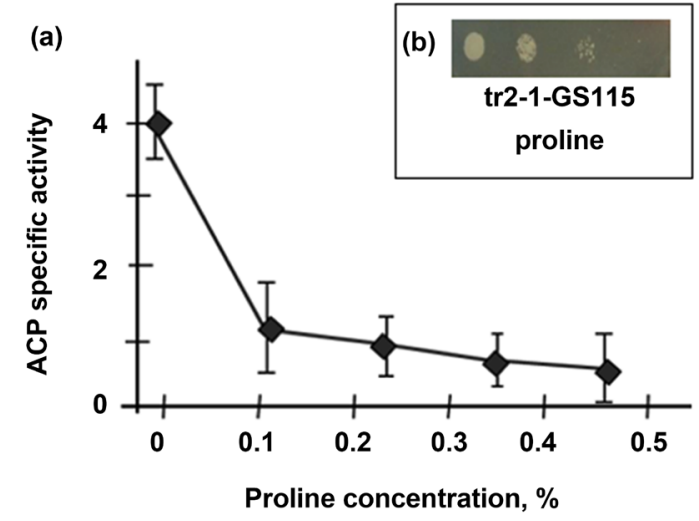

Figure 1. (a) ACP specific activity of $P$ p pastoris strain tr2-1-GS115 (PAOX1-PHO5 HIS4 phox) grown in media with methanol, ammonium sulfate $(0.46 \% \mathrm{w} / \mathrm{v})$ and different concentrations of proline. All measurements were done at least in 4 replicates with 2 ACP specific activity measurements for each. SEM is plotted as error bars; (b) Growth of tr2-1-GS115 strain on media with proline as sole source of carbon and nitrogen (P). 
Results demonstrate that $P$. pastoris are able to grow only on proline. Thus, repression of $M U T$-genes by this amino acid may be caused by its utilization as a carbon source.

2) Identification of $P$. pastoris and $S$. cerevisiae homologous proteins, which are targeted by Tor-signalling

To investigate, which other pathways downstream of Tor-kinase are involved in regulation of $A O X 1$ and $M U T$-genes, we searched for $P$. pastoris proteins homologous to $S$. cerevisiae proteins acting in retrograde regulation pathway and nutrient limitation. A bioinformatic analysis of $P$. pastoris genome was carried out. Using the BLAST algorithm, the amino acid sequences of proteins homologous to the $S$. cerevisiae Rtg1p, Rtg2p, Msn2p, Msn4p, Tor1p, Tor2p were identified (Table 3).

It was shown that $P$. pastoris Tor protein has a high degree of identity with the sequences of the $S$. cerevisiae Tor1p and Tor $2 \mathrm{p}$. The observation that only one protein is found in $P$. pastoris, can be explained by the fact that yeast $S$. cerevisiae underwent genome duplication during evolution [21]. Similarly, for the Msn2p and Msn4p, only one homologous protein PpMsn2/4 was detected in $P$. pastoris. Proteins homologous to $S$. cerevisiae Rtg1p and Rtg2p were detected. Analysis didn't give any results for Rtg3p when genome assembly described in [2] was used. A protein was identified using another genome assembly [22].

3) Construction of plasmids for introducing deletions into $P$. pastoris genome

To determine the effect of deletions in $P p R T G 1, P p R T G 2, P p M S N 2 / 4$ genes, on the regulation of the $A O X 1$ gene in $P$. pastoris, plasmids pJET1.2-PpRTG1 $\triangle Z e o R, p J E T 1.2-P p R T G 2 \triangle Z e o R$ and $p J E T 1.2-P p M S N 2 / 4 \triangle Z e o R$ were constructed. The coding sequences of $P p R T G 1, P p R T G 2, P p M S N 2 / 4$ genes were amplified by PCR using Rtg1F/Rtg1R, Rtg2F/Rtg2R, MsnF/MsnR primers. Chromosomal DNA of tr2-1-GS115 P. pastoris strain was used as the template. The obtained DNA fragments were cloned in pJET1.2/blunt plasmid.

$Z e o R$ gene coding sequence was PCR amplified using ZeoF/ZeoR primers and $p P I C Z a A$ plasmid as a template. ZeoR was cloned into pJET1.2-PpRTG1, pJET1.2-PpRTG2 and $p J E T 1.2-P p M S N 2 / 4$ causing deletions in coding sequences of target genes (Figure 2(a)). Resulting pJET1.2-PpRTG1 $\triangle$ ZeoR,

Table 3. Comparison of $P$. pastoris and $S$. cerevisiae protein sequences.

\begin{tabular}{cccccc}
\hline $\begin{array}{c}\text { S. cerevisiae } \\
\text { protein }\end{array}$ & $\begin{array}{c}\text { P. pastoris } \\
\text { protein }\end{array}$ & $\begin{array}{c}\text { Query } \\
\text { cover, } \%\end{array}$ & Identity, \% & $\begin{array}{c}\text { Protein reference } \\
\text { (UniProtKB/TrEMBL) }\end{array}$ & $\begin{array}{c}\text { Gene reference } \\
\text { (EnsemblGenomes) }\end{array}$ \\
\hline Rtg1 & PpRtg1 & 72 & 48 & C4QWX5 & PAS_chr1-1_0371 \\
Rtg2 & PpRtg2 & 99 & 52 & C4R4L3 & PAS_chr3_0452 \\
Rtg3 & PpRtg3? & 26 & 44 & AOA70166.1 (GenBank) & PAS_chr2-1_0723 \\
Msn2 & & 17 & 49 & & \\
Msn4 & PpMsn2/4 & 15 & 51 & C4R1J8 & PAS_chr2-1_0723 \\
Tor1 & PpTor & 97 & 55 & & \\
Tor2 & & 96 & 57 & C4R117 & PAS_chr2-1_0557 \\
\hline
\end{tabular}




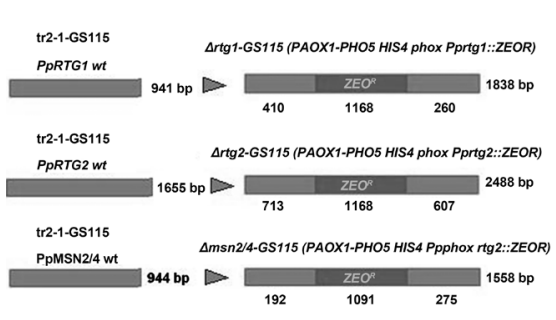

(a)

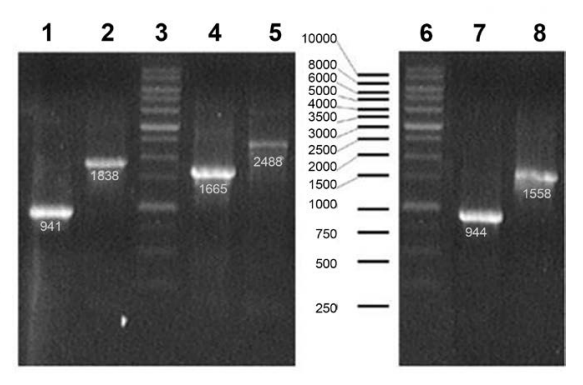

(b)

Figure 2. (a) Schematic representation of deletions in $\triangle \mathrm{rtg} 1-\mathrm{GS} 115$ (PAOX1-PHO5 HIS4 phox Pprtg1::ZEO ${ }^{R}$ ), $\Delta \mathrm{rtg} 2-\mathrm{GS} 115$ (PAOX1-PHO5 HIS4 phox Pprtg2::ZEO ${ }^{R}$ ) and $\triangle \mathrm{msn} 2 / 4-\mathrm{GS} 115$ (PAOX1-PHO5 HIS4 Ppphox rtg2::ZEO ${ }^{R}$ ) strains; (b) Electropherogram of PCR products (strain gDNA used for PCR/primers): 1 lane-control strain tr2-1-GS115/Rtg1F-Rtg1R primers; 2- $\operatorname{rtg1-GS115/Rtg1F-Rtg1R;~3.6-Ladder~} 1 \mathrm{~kb}$ (Evrogen, Russia); 4-tr2-1-GS115/Rtg2F-Rtg2R; 5- rtg2-GS115/Rtg2F-Rtg2R; 7-tr2-1-GS115 / MsnF-MsnR; 8- $\Delta \mathrm{msn2/4-GS115/MsnF-MsnR.}$

pJET1.2-PpRTG2 $\triangle Z e o R$ and $p J E T 1.2-P p M S N 2 / 4 \triangle Z e o R$ plasmids were analyzed using PCR and Sanger sequencing.

4) Generation of $P$. pastoris strains with deletions of $P p R T G 1, P p R T G 2$ and $P p M s n 2 / 4$ genes

Plasmids $p J E T 1.2-P p R T G 1 \triangle Z e o R, p J E T 1.2-P$ pRTG2 $\triangle Z e o R$ and PJET1.2-PpMSN2/4 $\triangle Z e o R$ were used as a template for PCR amplification of the PpRTG1::ZeoR, PpRTG2::ZeoR and PpMSN2/4::ZeoR fragments with Rtg1F/Rtg1R, Rtg2F/Rtg2R and MsnF/MsnR primers. In the resulting DNA fragments, the zeocin resistance gene $Z e o R$ is flanked by $P p R T G 1, P p R T G 2$ and $P p M S N 2 / 4$ gene sequences. Transformation of $P$. pastoris with these cassettes resulted in the replacement of $P p R T G 1, P p R T G 2$ and $P p M S N 2 / 4$ with the zeocin resistance gene through homologous recombination. tr2-1-GS115

(PAOX1-PHO5 HIS4 phox) was used as the recipient strain for transformation by electroporation. Transformants were selected on a YPDS medium with zeocin. Presence of deletions in resulting $\triangle \mathrm{rtg} 1-\mathrm{GS} 115$ (PAOX1-PHO5 HIS4 phox Pprtg1::ZEO $)^{R}$, $4 \mathrm{rtg} 2-\mathrm{GS} 115$ (PAOX1-PHO5 HIS4 phox Pprtg2::ZEO ${ }^{R}$ ) and $\triangle \mathrm{msn} 2 / 4-\mathrm{GS} 115$ (PAOX1-PHO5 HIS4 phoxPprtg 2::ZEO ${ }^{R}$ ) strains was proved using PCR (Figure 2(b)) and Sanger sequencing.

5) Phenotypic characteristic of $\Delta \mathrm{rtg} 1-\mathrm{GS} 115, \Delta \mathrm{rtg} 2-\mathrm{GS} 115$ and

\section{$\Delta \mathrm{msn} 2 / 4-\mathrm{GS} 115$ strains}

Phenotype of strains with deletions in the PpRTG1, PpRTG2 and $P p M S N 2 / 4$ genes was evaluated. Strains were grown on solid media GN, GP, MN and MP, containing glycerol $(\mathrm{G})$ or methanol $(\mathrm{M})$ as a carbon source and ammonium sulfate $(\mathrm{N})$ or proline $(\mathrm{P})$ as a nitrogen source, respectively. $P$. pastoris tr2-1-2-GS115 (PAOX1-PHO5 HIS4 phox) was used as a control. $10 \mu \mathrm{l}$ of cell suspensions $\left(10^{6}, 10^{5}, 10^{4}\right.$, and $10^{3}$ cells per $\left.\mathrm{ml}\right)$ were placed on the Petri dishes with these media and incubated for 4 days at $30^{\circ} \mathrm{C}$ (Figure 3 ).

On media with glycerol as a carbon source, growth of $\Delta \operatorname{rtg1-GS115,}$ 


\begin{tabular}{|c|c|c|c|c|}
\hline Media & $\begin{array}{c}\mathrm{GN} \\
\text { glycerol } \\
\mathrm{NH}^{+}\end{array}$ & $\begin{array}{c}\text { Gp } \\
\text { glycerol } \\
\text { proline }\end{array}$ & $\begin{array}{c}\mathrm{MN} \\
\text { methanol } \\
\mathrm{NH}^{+}\end{array}$ & $\begin{array}{c}\text { MP } \\
\text { methanol } \\
\text { proline }\end{array}$ \\
\hline$\Delta r \operatorname{rtg} 1-G S 115$ & 08 & 0. & & \\
\hline$\Delta r \operatorname{tg} 2-G S 115$ & & & & 20 落 \\
\hline$\Delta m s n 2 / 4-G S 11$ & 0.0. & & & . 웅 \\
\hline tr2-1-GS115 & 000 & 20 & $0-3$ & 20 \& \\
\hline
\end{tabular}

Figure 3. Growth of $\triangle \mathrm{rtg1-GS115}$ (PAOX1-PHO5 HIS4 phox Pprtg1::ZEO $)^{R}$, $\triangle \mathrm{rtg} 2-\mathrm{GS} 115$ ( $P A O X 1$ - $P H O 5$ HIS4 phox Pprtg2::ZEO ${ }^{R}$ ), $4 \mathrm{msn} 2 / 4-\mathrm{GS} 115$ (PAOX1-PHO5 HIS4 phox Ppmsn2/4::ZEO ${ }^{R}$ ) and tr2-1-GS115 (PAOX1-PHO5 HIS4 phox) on media with different carbon and nitrogen sources.

$\Delta$ rtg2-GS115, $\Delta \mathrm{msn} 2 / 4-\mathrm{GS} 115$ strains is similar to demonstrated by control strain tr2-1-GS115 either on ammonium sulfate (GN), or on proline (GP). On the other hand, $\Delta \mathrm{rtg} 1-\mathrm{GS} 115$ strain is unable to grow on a medium with methanol and ammonium sulfate (MN). $\Delta \mathrm{rtg} 2-\mathrm{GS} 115$ and $\Delta \mathrm{msn} 2 / 4-\mathrm{GS} 115$ demonstrate slower growth under these conditions. On medium with methanol and proline (MP) growth of $\Delta \mathrm{rtg} 1-\mathrm{GS} 115$ strain is slightly slower than of control tr2-1-GS115 strain. And growth of $\Delta \mathrm{rtg} 2-\mathrm{GS} 115$ and $\Delta \mathrm{msn} 2 / 4-\mathrm{GS} 115$ strains practically does not differ from the control.

6) Effect of deletions in $P p R T G 1, P p R T G 2$ and $P p M s n 2 / 4$ genes on $A O X I$ promoter activity

The addition of proline to the medium affects both the growth of $P$. pastoris strains on media with methanol and the activity of genes whose products are involved in the methanol utilization in these yeasts. Therefore, at this stage of the work, we investigated the effect of the deletions in PrRTG1, PrRTG2 and $P p M s n 2 / 4$ genes on the expression of main methanol metabolism gene $A O X I$.

The initial strain tr2-1-GS115 (PAOX1-PHO5 HIS4 phox) and obtained transformants contain the ACP reporter gene $\mathrm{PHO} 5$ under the control of the $A O X I$ promoter. These strains were first grown in GN medium with glycerol and ammonium sulfate for 48 hours, after which the biomass of the cells was transferred to media with methanol and various sources of nitrogen: proline and ammonium sulfate. In this case, the synthesis of acid phosphatase was induced by activation of the $A O X I$ promoter with methanol. After 40 hours of incubation, the specific activity of acid phosphatase was determined (Figure 4).

As shown in Figure 4 in a medium with ammonium sulfate, the level of $A O X 1$ gene expression is higher than in a medium with proline in all studied strains. Deletions in the $P p R T G 1$ and $P p R T G 2$ genes result in a decrease in $A O X I$ promoter activity in both proline and ammonium sulfate media. In $S$. cerevisiae Rtg1p-Rtg3p transcription factors bind to the sequence GGTCAC (R-box) in the promoter of its target genes [23]. Direct search using YEASTRACT database [24] did not show $S$. cerevisiae Rtg1p-Rtg3p binding sites in $A O X 1$ promoter sequence. 


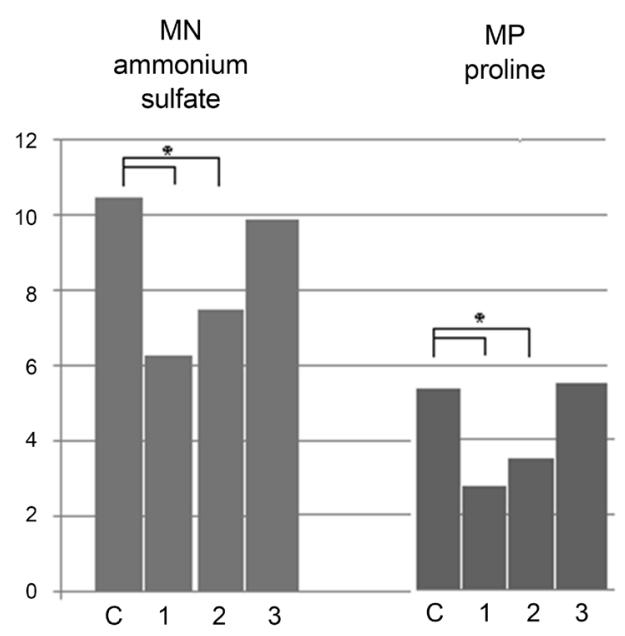

Figure 4. Specific activity of acid phosphatase synthesized by strains C. tr2-4-GS115 (PAOX1-PHO5 HIS4 phox), 1) Artg1-GS115 (PAOX1-PHO5 HIS4 phox Pprtg1::ZEO ${ }^{R}$, 2) $\triangle \mathrm{rtg} 2-\mathrm{GS} 115$ (PAOX1-PHO5 HIS4 phox Pprtg2::ZEO ${ }^{R}$ and 3) $\Delta \mathrm{msn} 2 / 4-\mathrm{GS} 115$ (PAOX1-PHO5 HIS4 phox Ppmsn2/4::ZEO ${ }^{R}$ ) after cultivation in media MN and MP with methanol and ammonium sulfate or proline respectively. All measurements were done at least in 4 replicates with 2 ACP specific activity measurements for each. ${ }^{*}-p<0.02$ (Mann-Whitney U-test).

Deletions of the PpMSN2/4 gene do not affect the activity of the $A O X 1$ promoter in media with methanol, and proline or ammonium sulfate as a nitrogen source.

\section{Discussion}

We show that $A O X 1$ promoter is repressed by proline even if ammonium sulfate is present in the media. Recent studies revealed that some amino acids (e.g. glutamate) can be used by $P$. pastoris as sole source of carbon and nitrogen [20]. We demonstrate that $P$. pastoris utilize proline in such way. It may be proposed, that when grown on media with methanol $P$. pastoris utilize proline as complex carbon and nitrogen source. This explains the repression of MUT-genes to optimal levels by Tor signaling pathway and also means that nitrogen regulation, especially NCR, differs in $P$. pastoris from one known for $S$. cerevisiae.

Deletion in $P p R T G 1$ gene results in inability of $P$. pastoris to grow on medium with methanol and ammonium sulfate. Deletions in $P p R T G 2$ and $P p M S N 2 / 4$ slow the growth of $P$. pastoris on such medium. These effects are compensated when $\Delta$ rtg1-GS115, $\Delta$ rtg2-GS115 and $\Delta \mathrm{msn} 2 / 4-G S 115$ strains are grown on glycerol instead of methanol, or when proline is used as sole nitrogen source. It should be noted that effects of these mutations on $P$. pastoris phenotype were not studied yet. In $S$. cerevisiae $r t g$ mutants demonstrate growth requirement for glutamate which itself is a precursor for synthesis of other amino acids and nucleotides [25]. In yeast, there are three known pathways for glutamate synthesis that use a-ketoglutarate as a common precursor of glutamate. S. cerevisiae can also degrade proline into glutmate via the proline utilization pathway in the mitochondria [26]. Thus, it may be proposed, that in P. pastoris metabolism of 
glutamate or it's precursor a-ketoglutarate changes when different carbon sources are used. Glutamate synthesis depends on retrograde regulation when cells are grown in media with ammonium sulfate and methanol, but is regulated in different way when glycerol is used as a carbon source. When proline is present in the media it is metabolized to glutamate, thus negating the effects of deletions in $P p R T G 1$ and $P p R T G 2$ genes.

We demonstrate that deletions in $P p R T G 1$ and $P p R T G 2$ decrease activity of $A O X 1$ promoter. Protein products of these genes may be involved in regulation of $A O X 1$ and their presence is required for full induction of $A O X 1$ and other $M U T$-genes in $P$. pastoris. Absence of Rtg1p-Rtg3p binding sites known for $S$. cerevisiae in $A O X 1$ promoter may allow suggesting, that in $P$. pastoris either Rtg-binding sites are different, or Rtg proteins are indirectly involved in regulation of $A O X 1$ promoter. For example, in $S$. cerevisiae Rtg1p-Rtg3p interact with negative retrograde regulators Bmh1p and Bmh2p. And in P. pastoris activity of Mxrlp, which is known to be the main inductor of $M U T$-genes [27], is regulated by $14-3-3$ protein that shows similarity to $S$. cerevisiae Bmhlp [28].

Neither of the deletions changed $A O X 1$ regulation by proline. Thus, there are some other proteins downstream of Tor-kinase which establish such regulation. It may be proposed that Tor-kinase complex may modify activity of proteins involved in $A O X 1$ regulation by carbon source, for example, Mxr1p and 14-3-3 protein homologous to $S$. cerevisiae Bmhlp. A model of such interactions was presented earlier [8].

\section{Conclusion}

P. pastoris is able to use proline as a sole source of carbon and nitrogen. $A O X 1$ promoter is repressed by proline even at low concentrations $(0.11 \% \mathrm{w} / \mathrm{v})$, regardless of ammonium sulfate presence in the media. $P p R T G 1$ gene is essential for growth on media with methanol as a carbon source and ammonium sulfate as a source of nitrogen. Deletions in $P p R T G 1$ and $P p R T G 2$ genes cause decrease in activity of $A O X 1$ promoter.

\section{Acknowledgements}

The reported study was funded by RFBR according to the research project No.18-34-00750. Equipment, provided by St. Petersburg State University Centre for Molecular and Cell Technologies was used in this study.

\section{References}

[1] Juturu, V. and Wu, J.C. (2018) Heterologous Protein Expression in Pichia pastoris. Latest Research Progress and Applications. Chembiochem, 19, 7-21. https://doi.org/10.1002/cbic.201700460

[2] De Schutter, K., Lin, Y.C., Tiels, P., Van Hecke, A., Glinka, S., Weber-Lehmann, J., Rouze, P., Van de Peer, Y. and Callewaert, N. (2009) Genome Sequence of the Recombinant Protein Production Host Pichia pastoris. Nature Biotechnology, 27, 561-566. https://doi.org/10.1038/nbt.1544 
[3] Anthony, C. (1982) The Biochemistry of Methylotrophs. Academic Press, New York.

[4] Veenhuis, M., Van Dijken, J.P. and Harder, W. (1983) The Significance of Peroxisomes in the Metabolism of One-Carbon Compounds in Yeasts. Advances in Microbial Physiology, 24, 1-82. https://doi.org/10.1016/S0065-2911(08)60384-7

[5] Ahmad, M., Hirz, M., Pichler, H. and Schwab, H. (2014) Protein Expression in Pichia pastoris. Recent Achievements and Perspectives for Heterologous Protein Production. Applied Microbiology and Biotechnology, 98, 5301-5317. https://doi.org/10.1007/s00253-014-5732-5

[6] Tschopp, J.F., Brust, P.F., Cregg, J.M., Stillman, C.A. and Gingeras, T.R. (1987) Expression of the lacZ Gene from Two Methanol-Regulated Promoters in Pichia pastoris. Nucleic Acids Research, 15, 3859-3876. https://doi.org/10.1093/nar/15.9.3859

[7] Rumjantsev, A.M., Padkina, M.V. and Sambuk, E.V. (2013) Effect of Nitrogen Source on Gene Expression of First Steps of Methanol Utilization Pathway in Pichia pastoris. Russian Journal of Genetics, 49, 394-400.

https://doi.org/10.1134/S102279541304011X

[8] Rumjantsev, A.M., Bondareva, O.V., Padkina, M.V. and Sambuk, E.V. (2014) Effect of Nitrogen Source and Inorganic Phosphate Concentration on Methanol Utilization and PEX Genes Expression in Pichia pastoris. The Scientific World Journal, 2014, 9 .

[9] Loewith, R., Jacinto, E., Wullschleger, S., Lorberg A. and Crespo, J.L., (2002) Two TOR Complexes, Only One of Which Is Rapamycin Sensitive, Have Distinct Roles in Cell Growth Control. Molecular Cell, 10, 457-468.

https://doi.org/10.1016/S1097-2765(02)00636-6

[10] Cardenas, M.E., Cutler, N.S., Lorenz, M.C., Di Como, C.J. and Heitman J. (1999) The TOR Signaling Cascade Regulates Gene Expression in Response to Nutrients. Genes \& Development, 13, 3271-3279. https://doi.org/10.1101/gad.13.24.3271

[11] Hardwick, J.S., Kuruvilla, F.G., Tong, J.K., Shamji A.F. and Schreiber S.L. (1999) Rapamycin-Modulated Transcription Defines the Subset of Nutrient-Sensitive Signaling Pathways Directly Controlled by the Tor Proteins. Proceedings of the National Academy of Sciences of the United States of America, 96, 14866-14870. https://doi.org/10.1073/pnas.96.26.14866

[12] Komeili, A., Wedaman, K.P., O'Shea, E.K. and Powers, T. (2000) Mechanism of Metabolic Control. Target of Rapamycin Signaling Links Nitrogen Quality to the Activity of the Rtg1 and Rtg3 Transcription Factors. Journal of Cell Biology, 151, 863-878. https://doi.org/10.1083/jcb.151.4.863

[13] Liu, Z. and Butow, R.A. (2006) Mitochondrial Retrograde Signaling. Annual Review of Genetics, 40, 159-185. https://doi.org/10.1146/annurev.genet.40.110405.090613

[14] Loewith, R. and Hall, M.N. (2011) Target of Rapamycin (TOR) in Nutrient Signaling and Growth Control. Genetics, 189, 1177-1201. https://doi.org/10.1534/genetics.111.133363

[15] Maniatis, T., Fritsch and Sambrook, E.F.J. (1982) Molecular Cloning: A Laboratory Manual. Cold Spring Harbor.

[16] Guthrie, C. and Fink, G.R. (1991) Guide to Yeast Genetics and Molecular Biology. Academic Press, Cambridge, 194.

[17] Cregg, J.M. (2007) Pichia Protocols. Methods in Molecular Biology, Vol. 389, Springer, Berlin. https://doi.org/10.1007/978-1-59745-456-8

[18] Samsonova, M.G., Padkina, M.V. and Krasnopevtseva, N.G. (1975) Genetic and Bi- 
ochemical Study of Acid Phosphatases from Saccharomyces cerevisiae: Genetic Control of Regulation of Acid Phosphatase II Synthesis. Genetika, 11, 104-115.

[19] Padkina, M.V., Krasnopevtseva, N.G. and Petrashen, M.G. (1974) Genetic and Biochemical Study of Acid Phosphatases from Saccharomyces cerevisiae: Characteristic of the Acid Phosphatases from Different Strains. Genetika, 10, 100-111.

[20] Sahu, U. and Rangarajan, P.N. (2016) Methanol Expression Regulator 1 (Mxr1p) Is Essential for the Utilization of Amino Acids as the Sole Source of Carbon by the Methylotrophic Yeast, Pichia pastoris. The Journal of Biological Chemistry, 291, 20588-20601. https://doi.org/10.1074/jbc.M116.740191

[21] Kellis, M., Patterson, N., Birren, B., Berger, B. and Lander, E.S. (2004) Methods in Comparative Genomics: Genome Correspondence, Gene Identification and Regulatory Motif Discovery. Journal of Computational Biology, 11, 319-355. https://doi.org/10.1089/1066527041410319

[22] Love, K.R., Shah, K.A., Whittaker, C.A., Wu, J., Bartlett, M.C., Ma, D., Leeson, R.L., Priest, M., Borowsky, J., Young, S.K. and Love, J.C. (2016) Comparative Genomics and Transcriptomics of Pichia pastoris. BMC Genomics, 17, 550. https://doi.org/10.1186/s12864-016-2876-y

[23] Jia, Y., Rothermel, B., Thornton, J. and Butow, R.A. (1997) A Basic Helix-Loop-Helix-Leucine Zipper Transcriptional Complex in Yeast Functions in a Signaling Pathway from Mitochondria to the Nucleus. Molecular and Cellular Biology, 17, 1110-1117. https://doi.org/10.1128/MCB.17.3.1110

[24] Teixeira, M.C., Monteiro, P.T., Palma, M., Costa, C., Godinho, C.P., Pais, P., Cavalheiro, M., Antunes, M., Lemos, A., Pedreira, T. and Sá-Correia, I. (2018) YEASTRACT, an Upgraded Database for the Analysis of Transcription Regulatory Networks in Saccharomyces cerevisiae. Nucleic Acids Research, 46, 348-353. https://doi.org/10.1093/nar/gkx842

[25] Liao, X. and Butow, R.A. (1993) RTG1 and RTG2: Two Yeast Genes Required for a Novel Path of Communication from Mitochondria to the Nucleus. Cell, 72, 61-71. https://doi.org/10.1016/0092-8674(93)90050-Z

[26] Brandriss, M.C. and Magasanik, B. (1979) Genetics and Physiology of Proline Utilization in Saccharomyces cerevisiae: Mutation Causing Constitutive Enzyme Expression. Journal of Bacteriology, 140, 504-507.

[27] Lin-Cereghino, G.P., Godfrey, L., de la Cruz, B.J., Johnson, S., Khuongsathiene, S. and Tolstorukov, I. (2006) Mxr1p, a Key Regulator of the Methanol Utilization Pathway and Peroxisomal Genes in Pichia pastoris. Molecular and Cellular Biology, 26, 883-897. https://doi.org/10.1128/MCB.26.3.883-897.2006

[28] Parua, P.K., Ryan, P.M., Trang, K. and Young, E.T. (2012) Pichia pastoris 14-3-3 Regulates Transcriptional Activity of the Methanol Inducible Transcription Factor Mxr1 by Direct Interaction. Molecular Microbiology, 85, 282-298.

https://doi.org/10.1111/j.1365-2958.2012.08112.x 